\title{
Memantine augmentation in clozapine-refractory schizophrenia: a randomized, double-blind, placebo- controlled crossover study
}

\author{
S. R. T. Veerman ${ }^{1 *}$, P. F. J. Schulte ${ }^{2}$, J. D. Smith ${ }^{3}$ and L. de Haan $^{4}$ \\ ${ }^{1}$ Mental Health Service Organization North Holland North, Community Mental Health Division, Flexible Assertive Community Treatment, \\ Alkmaar, The Netherlands \\ ${ }^{2}$ Mental Health Service Organization North Holland North, Division for Specialized Treatment, Treatment Center for Bipolar Disorders, Alkmaar, \\ The Netherlands \\ ${ }^{3}$ Department of Psychiatry and Behavioral Sciences, Northwestern University, Feinberg School of Medicine, Center for Prevention Implementation \\ Methodology, Chicago, IL, USA \\ ${ }^{4}$ Early Psychosis Department, Academic Medical Center, University of Amsterdam, Academic Psychiatric Center, Arkin, Amsterdam, The \\ Netherlands
}

Background. Dysfunction of neuroplasticity due to $\mathrm{N}$-methyl-D-aspartate (NMDA) receptor hypofunction may be a causal factor for memory and executive dysfunctioning in schizophrenia. Deregulation of NMDA transmission in the prefrontal cortex may also explain negative and positive symptoms. Clozapine augmentation with memantine targets altered NMDA receptor-mediated neurotransmission in schizophrenia and showed substantial beneficial effects on several symptom domains in a small proof-of-concept study. We evaluate effects of memantine add-on treatment to clozapine for memory and executive function, and negative and positive symptoms in schizophrenia.

Method. Clozapine-treated patients with refractory schizophrenia were randomly assigned to 12 weeks of double-blind adjunctive treatment with memantine $(n=26)$ or placebo $(n=26)$. Crossover occurred after a 2-week placebo wash-out period. Primary endpoints were change from baseline to 12 weeks treatment and 14 weeks to 26 weeks treatment on memory and executive function using the Cambridge Neuropsychological Test Automated Battery (CANTAB), Positive and Negative Syndrome Scale (PANSS), and Clinical Global Impression Severity Scale (CGI-S). Side effects were assessed using the Liverpool University Neuroleptic Side-Effect Rating Scale.

Results. When compared with placebo, memantine improved a composite memory score comprising verbal recognition memory and paired associates learning task scores on the CANTAB (effect size $=0.30$ ) and PANSS negative subscale score (effect size $=0.29$ ). Side effects were mild and transient.

Conclusions. In patients with clozapine-treated refractory schizophrenia, memantine addition significantly improved verbal and visual memory and negative symptoms without serious adverse effects. These results justify further investigations on long-term memantine augmentation to clozapine in treatment-resistant schizophrenia.

Received 25 September 2015; Revised 30 December 2015; Accepted 4 February 2016; First published online 6 April 2016

Key words: Antipsychotics, cognitive functioning, memantine, randomized controlled trials, therapy-resistant schizophrenia.

\section{Introduction}

Although clozapine is efficacious for treatmentresistant schizophrenia patients, as many as $70 \%$ of patients show only a partial response (Hasan et al. 2012). Polypharmacy is frequently used; however, evidence concerning additional pharmacological treatment of refractory schizophrenia is limited

* Address for correspondence: S. R. T. Veerman, M.D., Mental Health Service Organization North Holland North, Community Mental Health Division, Flexible Assertive Community Treatment, Oude Hoeverweg 10, 1816 BT Alkmaar, The Netherlands.

(Email: s.veerman@ggz-nhn.nl)
(Muscatello et al. 2014; Veerman et al. 2014a,b). Novel avenues of research are needed to bring about improved drug treatment of schizophrenia.

On the basis of the glutamate hypothesis, with hypofunction of the glutamate $N$-methyl-D-aspartate (NMDA) receptor as an underlying mechanism for schizophrenia (Stone et al. 2007; Kantrowitz \& Javitt, 2010), glutamate modulators can be seen as promising antipsychotic agents (Veerman et al. 2014c). The glutamate hypothesis of schizophrenia stipulates that hypofunction of the NMDA receptor is responsible for excitotoxic neurodegeneration, dysfunction of neuroplasticity and dysregulation of downstream neurons in response to glutamate release, resulting in cognitive

This is an Open Access article, distributed under the terms of the Creative Commons Attribution licence (http://creativecommons.org/licenses/by/4.0/), which permits unrestricted re-use, distribution, and reproduction in any medium, provided the original work is properly cited. 
impairment and negative symptoms (Javitt \& Zukin, 1991; Bressan \& Pilowsky, 2000; Howes \& Kapur, 2009; Orellana \& Slachevsky, 2013). Positive symptoms may develop through disinhibition of prefrontal cortical $\gamma$-amino butyric acid (GABA) interneurons, which are responsible for recurrent inhibition of pyramidal neurons (Homayoun \& Moghaddam, 2007).

Memantine acts as a low-affinity type, uncompetitive, non-selective and voltage-dependent NMDA receptor antagonist (Parsons \& Gilling, 2007). Memantine is licensed for treatment of moderate-tosevere Alzheimer's disease (AD) (Areosa et al. 2005). Efficacy in patients with moderate-to-severe AD was demonstrated in a meta-analysis of six randomized placebo-controlled trials showing modest beneficial effects on global status and cognition after treatment with memantine (Winblad et al. 2007). Memantine has a favorable safety and tolerability profile (Farlow et al. 2008).

Favorable effects of memantine addition to nonclozapine antipsychotics described in case reports and open studies were replicated in only one of three placebo-controlled trials of memantine in combination with non-clozapine antipsychotics (Lieberman et al. 2009; Lee et al. 2012; Rezaei et al. 2013). However, memantine is thought to be more promising as an adjunctive therapy to clozapine than to non-clozapine antipsychotics. One small 12-week randomized, placebo-controlled trial $(n=21)$ demonstrated efficacy of memantine augmentation in patients with partial remission of negative symptoms of schizophrenia on clozapine treatment with large effect sizes (ESs) for overall symptoms $(\mathrm{ES}=2.75)$, positive symptoms $(E S=1.38)$, negative symptoms $(E S=3.33)$ and global cognitive functioning $(E S=-1.32)$ (de Lucena et al. 2009).

The favorable effects of memantine augmentation to clozapine may be related to their conjunct action on NMDA receptors. This particular combination modulates glutamatergic neurotransmission at multiple levels (Veerman et al. 2014c): clozapine induces both up-regulation of $\alpha$-amino-3-hydroxy-5-methyl-4isoxazolepropionic acid (AMPA) receptors and NMDA receptors (Yeun et al. 2010; Tanahashi et al. 2012), and memantine may enhance further up-regulation of NMDA receptors causing activation in the presence of a strong stimulus (Joshi et al. 2007). NMDA receptors are highly expressed in the hippocampus (Bliss \& Collingridge, 1993). Improvement of hippocampal dysfunction and functional connectivity between brain circuits, involving the prefrontal cortex (PFC) through NMDA-receptor mediated neuroplasticity, explains why combination therapy of clozapine and memantine possibly targets two specific cognitive domains: impaired memory and executive function.
Inspired by the unique functional psychopharmacological characteristics of the memantine-clozapine combination and the substantial positive findings of the first proof-of-concept study, we conducted a second, larger and more elaborate trial studying effects of adjunctive memantine therapy on memory, executive function and symptom severity in clozapine-treated patients suffering from refractory schizophrenia.

\section{Method}

\section{Study design}

The study was approved by the Central Committee on Research Involving Human Subjects and the Medical Research Ethics Committee (MREC) of Alkmaar Medical Center and was conducted in accordance with the Declaration of Helsinki (World Medical Association, 2013). The study was a 26-week singlecenter, double-blind trial that was randomized and placebo controlled. The trial consisted of two crossover, 12-week treatment phases and a placebo washout period of 2 weeks in the 13th and 14th week to avoid carryover effects (Fig. 1). Clozapine dosage and use of concomitant medications were at the discretion of the treating psychiatrist and remained as much unaltered as possible throughout the study. Subjects were randomly assigned to receive an identical number of either memantine or placebo tablets. During the memantine phase a dosage of $10 \mathrm{mg}$ taken once daily was built up after 1 week to $20 \mathrm{mg}$ taken once daily during 11 weeks as add-on therapy to ongoing clozapine treatment. The dose of $20 \mathrm{mg} /$ day was similar to the dosage used in all four randomized placebo-controlled trials in patients with schizophrenia (de Lucena et al. 2009; Lieberman et al. 2009; Lee et al. 2012; Rezaei et al. 2013).

Randomization to starting with either memantine or placebo was designated on a 1:1 basis in blocks of four. The allocation sequence was produced independently by the pharmacist of the VU Medical Center in Amsterdam. The code was concealed for patients, care providers, raters and investigators until all subjects had completed the trial and data had been entered into a computer data file.

\section{Study population, inclusion and exclusion criteria}

The study was performed from August 2013 until August 2014, at 12 Flexible Assertive Community Treatment (FACT) facilities of the Mental Health Service Organization North Holland North (Netherlands) (van Veldhuizen, 2007). The original eligibility criterion of 'out-patients' was broadened to patients living either independently or in a sheltered home and patients admitted to open long-stay wards, receiving 


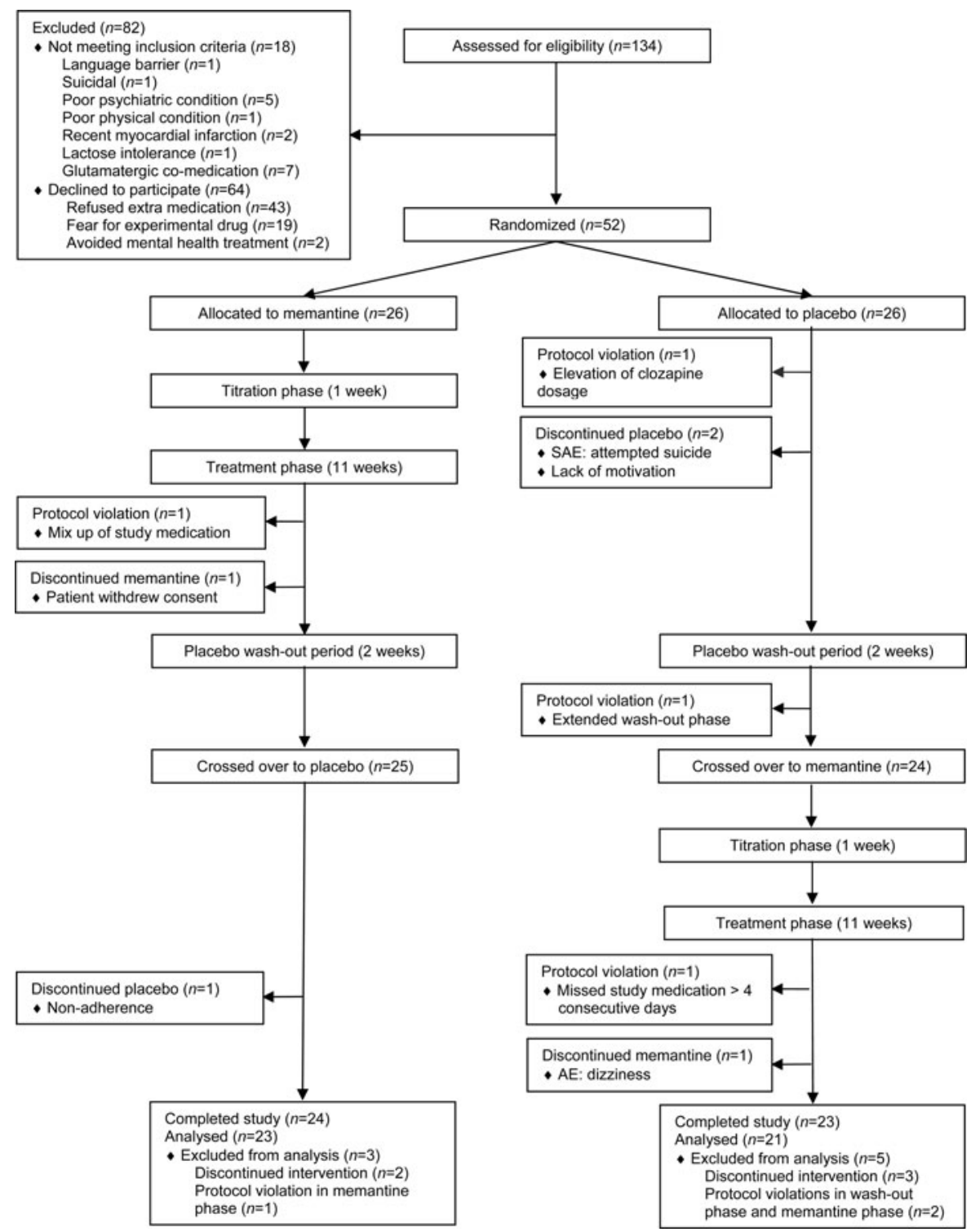

Fig. 1. Patient disposition in a double-blind, randomized, placebo-controlled trial of memantine as adjunctive treatment to clozapine in refractory schizophrenia. SAE, Serious adverse event; AE, adverse event.

care from an out-patient facility. This was reported to the MREC of Alkmaar Medical Center. Eligible subjects were between the ages of 18 and 60 years, met Diagnostic and Statistical Manual of Mental Disorders, fourth edition (DSM-IV) criteria for schizophrenia on the Mini International Neuropsychiatric Interview Plus (MINI-Plus) (Overbeek et al. 1999), and failed to achieve remission criteria proposed by Andreasen et al. (2005), defined as simultaneous ratings of mild or less ( $\leqslant 3$ points) on eight of the following Positive and Negative Syndrome Scale (PANSS) items: P1 delusions, G9 unusual thought content, P3 hallucinatory behavior, P2 conceptual disorganization, G5 mannerisms and posturing, N1 blunted affect, N4 passive or apathetic social withdrawal, N6 lack of spontaneity and flow of conversation. At inclusion, duration of clozapine therapy was at least 6 months with a minimum of 12 weeks with a clozapine plasma level above $350 \mathrm{ng} / \mathrm{ml}$ or intolerability to achieve this threshold (Schulte, 2003). Patients with a recent deterioration needing treatment in an acute treatment ward were not included. Other exclusion criteria included pregnancy, lactating women, and female subjects without adequate contraception, known hypersensitivity to memantine, co-medication with glutamate modulators, lactose intolerance, uncontrolled epilepsy, myocardial infarction, uncontrolled hypertension, renal insufficiency, liver failure or AD (Wesemann et al. 1983). The sample size was calculated at 52 , based on an ES of $0.55(\alpha=0.05$, power $=0.80)$ and accounting for an 
estimated discontinuation rate of $20 \%$. After complete description of the study to the subjects, written informed consent was obtained by the principal investigator. Care providers distributed study medication and monitored compliance on a daily basis in patients in sheltered homes and open long-stay wards and on a weekly basis in out-patients.

\section{Clinical assessments}

We used the Cambridge Neuropsychological Test Automated Battery (CANTAB), a computerized, nonlinguistic cognitive testing battery (Levaux et al. 2007). Test selection was based on six cognitive domains, recommended by the Measurement and Treatment Research to Improve Cognition in Schizophrenia (MATRICS): reaction time and psychomotor speed, sustained visual attention, verbal memory, visuospatial memory, learning and association ability, working visuospatial memory and strategy use, spatial planning and motor control and emotion recognition (Nuechterlein et al. 2008; Barnett et al. 2010). One cognitive domain of the MATRICS Consenus Cognitive Battery (MCCB) was not assessed, because Intra/Extra-Dimensional Set-Shifting (IED) for reasoning and problem solving was too difficult for our patient population with severe cognitive disturbances.

Two cognitive domains were selected as primary outcomes: memory and executive function (see Table $2 t^{1}$ ). Memory was assessed by computing a composite score of the sum of the CANTAB scores of four tasks: verbal recognition memory (VRM) free recall and VRM recognition, and paired associates learning (PAL) total errors and PAL first trial memory score. To reduce practice effects a parallel form of the VRM task, equivalent in difficulty, was used for the second and fourth measurement. Executive function was assessed by computing a composite of three CANTAB task scores: One Touch Stockings of Cambridge (OTS) problems solved on first choice, and spatial working memory (SWM) strategy and SWM between errors.

The PANSS was used to assess severity of positive, negative and total symptoms of schizophrenia (Kay et al. 1987). We assessed the effect of memantine on two subdomains of negative symptoms: (1) expressive deficits [flat affect (N1), poor rapport (N3), lack of spontaneity and flow of conversation (N6), mannerisms and posturing (G5), motor retardation (G7) and avolition (G13)]; and (2) social amotivation [emotional withdrawal (N2), passive/apathetic social withdrawal

+ The notes appear after the main text.
(N4) and active social avoidance (G16)] (Liemburg et al. 2013; Millan et al. 2014). Global severity of psychopathology was determined by using the Clinical Global Impression Severity Scale (CGI-S) (Guy, 1976).

Careful clinical procedures were performed to assess safety and tolerability of memantine add-on therapy to clozapine. Physical examination included measurements of waist circumference and blood pressure. Regular controls of white blood cell count and differentiation were combined with measurements of liver and renal function, blood glucose, lipids and plasma clozapine level (12 $\pm 0.5 \mathrm{~h}$ after ingestion). The occurrence and intensity of side effects were assessed by selfrating on the Liverpool University Neuroleptic Side-Effect Rating Scale (LUNSERS) (Day et al. 1995) augmented with rating of Likert scales for possible side effects of memantine (thrombosis, dyspnoea, and mycosis).

All outcomes were rated before treatment initiation, after 12 weeks, after 14 weeks, and after 26 weeks. Two raters were trained in diagnostic interviewing and all clinical assessments. Inter-rater exact and adjacent agreement (within one scale point) was $96 \%$ for the PANSS, based on seven assessments (two live patient interviews and five videotaped patient interviews).

Adverse events (AEs) were defined as any undesirable experience occurring to a subject during the study, whether or not they were considered to be related to memantine ingestion. All AEs, reported by either the subject or treatment staff, were recorded. Admission to a psychiatric hospital was no reason to break the code or for withdrawal from the study. A medical emergency was the only reason to break the code and withdraw the subject from the study.

\section{Statistical analysis}

To determine the effects of memantine on the hypothesized cognitive functions, schizophrenia symptoms, safety measures, and side effects, the two phases (memantine or placebo) of the crossover trial were compared using a linear mixed-effects model conducted in SPSS Statistics version 22.0.0 (SPSS Inc., 2014). This analytic approach can estimate random and fixed effects simultaneously (Putt \& Chinchilli, 1999). A natural log transformation was applied to cognitive function scores assessed via the CANTAB, which are non-normally distributed, so that estimates from the linear mixed-effects models would be trustworthy.

We conducted the analyses using an intention-totreat (ITT) analytic approach and a per-protocol analytic approach, which included only protocol completers. Protocol completion was defined as having completed both treatment phases without a serious protocol 
violation in the memantine phase. There was no significant difference in study completion rate by random group assignment (group $1=23 / 26$, group $2=21 / 26$; $\chi_{1}^{2}=1.209, p=0.47$ ). We also tested a number of covariates in the model, which are potentially related to the dependent variables. Covariates included patient age and gender, years of education, age of onset, duration of psychosis and duration of untreated psychosis. We followed the backwards trimming method described by Singer \& Willett (2003) to construct our models: as covariates were entered into the model, one at a time, those that were significantly related to one of the model's parameters were retained. Only the patient's years of education variable was related to the slope paramater; thus, this variable was retained in the final model and the others were discarded.

We first tested a model with random intercepts. However, the models failed to converge or produced errors in the Hessian matrix, so the intercept parameter was fixed to ensure trustworthy parameter estimates. The slope parameter was treated as a fixed effect after it was found that models with random slopes resulted in worse model fit. This indicates that models with fixed intercepts and slopes (i.e. constraining these parameters to be equal across participants) do not significantly differ from models in which these parameters are individually estimated. All tests of significance were two-tailed, and $\alpha$ was set to 0.05 . Standardized ESs (Cohen's $d$ ) were calculated (Cohen, 1988). We performed a post-hoc analysis to assess whether memantine had a more pronounced effect on expressive deficits or social amotivation. To evaluate possible differences between in-patients admitted to long-stay wards and other included patients we performed a post-hoc analysis of demographic variables and baseline characteristics and also conducted a post-hoc analysis of out-patients, excluding patients admitted to long-stay wards.

\section{Reliability of analyses}

To include the full, randomized sample in the analyses, restricted maximum likelihood estimation was used, which has been shown to provide unbiased estimates when data are missing at random or missing completely at random (MCAR) (Little \& Rubin, 2002). There was some degree of missing data in our sample (see Tables 2 and 3 and online Supplementary Tables S1 and S2 for valid $n^{\prime}$ s), but the data were determined to be MCAR (39) $\left(\chi_{737}^{2}=144.40, p=1.00\right)$, so the missing data did not introduce bias into the analyses.

Two steps were taken in the analytic strategy to address unique sources of potential bias in the crossover design: (1) a period effect parameter and a period $\times$ treatment interaction were tested to determine whether the order in which memantine was received was related to the outcome and whether there was a larger effect in one of the phases of the trial2; and (2) carryover effects were controlled for in all analyses.

Other possible confounders were analysed, such as change in clozapine dosage, concomittant medication, substance use, and use of psychotherapy during the study. The element of expectation of the placebo response was tested by examining whether pretrial expectations of positive benefits of memantine moderated the effect on the outcomes of active drug and placebo. Further, we analysed the degree of successful blinding by examining the degree of accurate appraisal of receipt of memantine from the perspective of the patient and the rater.

\section{Results}

\section{Baseline characteristics}

Fig. 1 presents participant screening and enrolment flow data. A total of 134 patients were screened, of whom 116 patients met inclusion criteria; 64 eligible patients refused participation. The remaining 52 patients gave informed consent and were enrolled. Table 1 presents demographic and clinical characteristics of the study population. Omnibus tests revealed that the two groups did not differ on any parameter except for significantly higher expectations for improvement in daily activities and living conditions in the group first assigned to placebo, compared with the group first assigned to memantine. A post-hoc analysis showed no significant differences between the six in-patients and the 46 out-patients on any of the demographic variables or baseline characteristics.

\section{Clinical efficacy results}

Analysis of effects using an ITT approach, presented in Table 2, indicated that all effects were in the direction of desired effect. The following primary outcome variables significantly improved during the memantine phase in comparison with the placebo phase: memory composite $\left(F_{4,655}, \mathrm{ES}=0.30, p=0.032\right)$; PANSS negative symptoms $\left(F_{1,84}=4.170, \mathrm{ES}=0.29, p=0.043\right)$. Other primary outcomes did not significantly improve after addition of memantine compared with placebo: executive function composite $\left(F_{1,84}=4.655, \mathrm{ES}=0.12, p=0.395\right)$; PANSS positive symptoms $\left(F_{1,84}=1.008, \mathrm{ES}=0.15, p=0.299\right)$; PANSS total symptoms $\left(F_{1,84}=1.869, \mathrm{ES}=0.19, p=\right.$ $0.174)$; CGI $\left(F_{1,84}=0.591, \mathrm{ES}=0.11, p=0.443\right)$. A post-hoc analysis on PANSS negative symptoms showed that memantine had a more pronounced effect on the expressive deficits subscale score $(E S=0.17)$ compared with the social amotivation subscale score $(E S=0.01)$. Table 2 contains the results of analyses on the 
Table 1. Patient demographics and baseline characteristics

\begin{tabular}{|c|c|c|c|c|}
\hline \multirow[b]{2}{*}{ Characteristic } & \multirow[b]{2}{*}{$n(\%)$} & \multirow[b]{2}{*}{ Mean (S.D.) } & \multicolumn{2}{|l|}{ Omnibus test } \\
\hline & & & $\chi^{2} / F$ & $p$ \\
\hline Gender & & & $\chi_{1}^{2}=0.923$ & 0.52 \\
\hline Female & $13(25)$ & & & \\
\hline Male & $39(75)$ & & & \\
\hline Age, years & & $42.35(9.55)$ & $F_{1,51}=3.165$ & 0.08 \\
\hline Years of education & & $12.23(1.79)$ & $F_{1,51}=0.596$ & 0.44 \\
\hline Education level & & & $\chi_{1}^{2}=0.202$ & 0.90 \\
\hline Low & $28(53.8)$ & & & \\
\hline Middle & $17(32.7)$ & & & \\
\hline High & $28(13.5)$ & & & \\
\hline \multicolumn{5}{|l|}{ Living conditions } \\
\hline Independently & $30(57.7)$ & & & \\
\hline Sheltered home & $16(30.8)$ & & & \\
\hline Long-stay department & $6(11.5)$ & & & \\
\hline Age of onset, years & & $19.46(4.68)$ & $F_{1,51}=2.848$ & 0.10 \\
\hline Duration of untreated psychosis, months & & $35.04(39.80)$ & $F_{1,51}=0.818$ & 0.37 \\
\hline Duration of illness, years & & $22.88(7.99)$ & $F_{1,51}=1.24$ & 0.27 \\
\hline Alcohol use & $18(34.6)$ & & $\chi_{1}^{2}=0.000$ & 1.00 \\
\hline Cannabis use & $9(17.3)$ & & $\chi_{1}^{2}=1.209$ & 0.47 \\
\hline Cocaine use & $1(1.9)$ & & $\chi_{1}^{2}=1.020$ & 1.00 \\
\hline Amphetamine use & $1(1.9)$ & & $\chi_{1}^{2}=1.020$ & 1.00 \\
\hline Clozapine daily dose, $\mathrm{mg}$ & & $350.00(182.84)$ & $F_{1,51}=0.171$ & 0.68 \\
\hline Clozapine monotherapy (single antipsychotic) & $36(69.2)$ & & $\chi_{1}^{2}=2.342$ & 0.22 \\
\hline Combination clozapine + second antipsychotic ${ }^{a}$ & $16(30.8)$ & & $\chi_{1}^{2}=3.250$ & 0.13 \\
\hline Combination clozapine + antidepressant & $30(57.7)$ & & $\chi_{1}^{2}=0.315$ & 0.78 \\
\hline Combination clozapine + mood stabilizer ${ }^{b}$ & $6(11.5)$ & & $\chi_{1}^{2}=3.014$ & 0.19 \\
\hline Combination clozapine + benzodiazepine & $18(34.6)$ & & $\chi_{1}^{2}=0.000$ & 1.00 \\
\hline Psychotherapy during past 6 months & $4(7.7)$ & & $\chi_{1}^{2}=0.000$ & 1.00 \\
\hline Family members or partners involved in the study & $26(50.0)$ & & $\chi_{1}^{2}=4.600$ & 0.47 \\
\hline Expected improvement due to memantine & & $3.50(0.918)$ & $F_{1,51}=0.818$ & 0.37 \\
\hline None & $2(3.8)$ & & & \\
\hline Very little & $3(5.8)$ & & & \\
\hline Little & $20(38.5)$ & & & \\
\hline Much & $21(40.4)$ & & & \\
\hline Very much & $6(11.5)$ & & & \\
\hline Expected improvement in personal hygiene & & $2.19(1.37)$ & $\chi_{4}^{2}=4.671$ & 0.46 \\
\hline Expected improvement in personal relationships & & $2.75(1.17)$ & $\chi_{4}^{2}=3.444$ & 0.49 \\
\hline Expected improvement in daily activities & & $3.00(1.21)$ & $\chi_{4}^{2}=12.600$ & 0.01 \\
\hline Expected improvement in living conditions & & $2.35(1.27)$ & $\chi_{4}^{2}=11.200$ & 0.04 \\
\hline Expected improvement in finances & & $1.83(1.18)$ & $\chi_{4}^{2}=3.586$ & 0.17 \\
\hline
\end{tabular}

S.D., Standard deviation.

${ }^{a}$ Eleven patients received aripiprazole, two patients received quetiapine, one patient received olanzapine and one patient received zuclopenthixol acetate.

${ }^{\mathrm{b}}$ Four patients received valproate and two patients received lithium.

individual CANTAB tasks comprising the two composite scores for reference only. No specific hypotheses were tested concerning the individual CANTAB tasks.

This pattern of significant results in the ITT approach was consistent with the per-protocol analyses: memory composite $\left(F_{4,150}, \mathrm{ES}=0.31, p=0.043\right)$; and PANSS negative symptoms $\left(F_{1,72}=3.514, \mathrm{ES}=0.21, p\right.$
$=0.043$ ). Tables 2 and 3 and online Supplementary Tables S1 and S2 summarize results and statistics of primary outcomes, side effects and safety measures.

A post-hoc analysis showed no evidence to suggest that the six patients admitted to long-stay wards responded differently to memantine than the 46 outpatients. In comparison with the full sample of 52 
Table 2. Intention-to-treat analysis of primary treatment effects ${ }^{\mathrm{a}}$

\begin{tabular}{|c|c|c|c|c|c|}
\hline \multirow[b]{2}{*}{ Variable } & \multirow[b]{2}{*}{$\mathrm{CO}$} & \multicolumn{4}{|c|}{ Intention to treat $(n=52)$} \\
\hline & & $n$ & $F$ test & ES & $p$ \\
\hline \multicolumn{6}{|l|}{$\begin{array}{l}\text { Cognitive domains and } \\
\text { CANTAB tasks }\end{array}$} \\
\hline \multicolumn{6}{|l|}{ Verbal memory } \\
\hline $\begin{array}{l}\text { VRM free recall - total } \\
\text { correct (phase 1) }\end{array}$ & 0.00 & 40 & 11.818 & $0.48^{*}$ & 0.001 \\
\hline $\begin{array}{l}\text { VRM recognition - } \\
\text { total correct }\end{array}$ & 0.09 & 40 & 1.421 & 0.17 & 0.235 \\
\hline \multicolumn{6}{|l|}{$\begin{array}{l}\text { Associative learning and } \\
\text { short-term visuospatial } \\
\text { memory }\end{array}$} \\
\hline $\begin{array}{l}\text { PAL total errors } \\
\text { (adjusted) }\end{array}$ & 0.04 & 37 & 1.219 & -0.15 & 0.271 \\
\hline $\begin{array}{l}\text { PAL first trial memory } \\
\text { score }\end{array}$ & 0.09 & 37 & 5.778 & $0.34^{*}$ & 0.017 \\
\hline $\begin{array}{l}\text { Memory composite } \\
\text { Working visuospatial } \\
\text { memory and strategy } \\
\text { use }\end{array}$ & 0.00 & 37 & 4.655 & $0.30^{*}$ & 0.032 \\
\hline SWM strategy & 0.32 & 37 & 0.159 & -0.06 & 0.690 \\
\hline SWM between errors & 0.47 & 37 & 1.522 & -0.17 & 0.219 \\
\hline \multicolumn{6}{|l|}{$\begin{array}{l}\text { Visual planning, } \\
\text { reasoning and } \\
\text { impulsivity }\end{array}$} \\
\hline $\begin{array}{l}\text { OTS problems solved } \\
\text { on first choice }\end{array}$ & 0.02 & 39 & 0.048 & 0.03 & 0.827 \\
\hline $\begin{array}{l}\text { Executive function } \\
\text { composite }\end{array}$ & 0.47 & 37 & 0.726 & 0.12 & 0.395 \\
\hline CGI-S & 0.32 & 47 & 0.591 & 0.11 & 0.443 \\
\hline PANSS-P & 0.02 & 44 & 1.088 & 0.15 & 0.299 \\
\hline PANSS-N & 0.01 & 44 & 4.170 & $0.29^{*}$ & 0.043 \\
\hline PANSS total & 0.00 & 44 & 1.869 & 0.19 & 0.174 \\
\hline
\end{tabular}

CO, Carryover effect ( $p$ value of paired $t$ test); ES, effect size (Cohen's $d$ ); CANTAB, Cambridge Neuropsychological Test Automated Battery; VRM, verbal recognition memory-immediate (free recall) and verbal recognition memory-delayed (recognition); PAL, paired associates learning; SWM, spatial working memory; OTS, One Touch Stockings of Cambridge; CGI-S, Clinical Global Impression Severity Scale; PANSS, Positive and Negative Syndrome Scale; PANSS-P, PANSS positive subscale; PANSS-N, PANSS negative subscale; PANSS total, PANSS total symptom score.

a All effects were in the direction of the desired effect.

* Significant beneficial effect.

patients, the ESs were nearly identical in magnitude (data available on request).

\section{Possible confounders}

Tests for period effects and period $\times$ treatment interaction were non-significant across all outcomes.
When matched-pair $t$ tests were used to compare scores from the first baseline to the second baseline of the trial, carryover effects were significant for the memory composite from the CANTAB, PANSS positive, negative, and total scores. $t$ Tests and a repeatedmeasures analysis of variance indicated no significant differences in clozapine levels across the four assessment times in the trial, suggesting that memantine has no effect on clozapine levels. Clozapine dosage (mean $350 \mathrm{mg}$, range $=75-1000 \mathrm{mg}$ ) remained unaltered in all subjects except in one subject in the placebo phase whose clozapine dosage was increased with $175 \mathrm{mg}$ because of agitation and verbal aggression. Alterations in concomitant medications throughout the study were limited to changes in benzodiazepines in one subject in the placebo phase. Use of substances or psychotherapy did not significantly change during the trial (see online Supplementary Table S3). Tests of moderation based on low and high levels of expectation for improvement prior to beginning the trial revealed that the element of expectation did not contribute to the placebo effect. Blinding was successful, in that $45.7 \%$ of patients guessed correctly which group they had been randomized to. The raters were correct in $21.7 \%$ of cases.

\section{Safety and tolerability}

No significant changes in liver and renal function were observed. Compared with placebo, memantine did not significantly affect metabolic parameters, such as waist circumference, blood pressure, blood glucose or lipids (see Table 3). The only significant increase in reported side effects while taking memantine was found on the Allergic Reactions subscale of the LUNSERS (rash, sensitivity to sun, unusual skin marks, and itchy skin).

Of all AEs (see Table 4), one report of dizziness, a common side effect of memantine in elderly patients with AD, was probably related to memantine. Complaints of dizziness were alleviated within 5 days of discontinuation of study medication. There were two reports of temporary increase in constipation, which were rated as possibly related to memantine. Both participants had been already treated with laxatives because of clozapine-induced constipation. We observed one serious AE (a suicide attempt during the placebo phase).

\section{Discussion and conclusions}

Inspired by the unique psychopharmacological characteristics of the memantine-clozapine combination and the substantial positive findings of the first proof-of-concept study we conducted a second proofof-concept study with a larger sample size and a 
Table 3. Side effects and safety measures

\begin{tabular}{|c|c|c|c|c|c|c|c|c|}
\hline \multirow[b]{2}{*}{ Variable } & \multirow[b]{2}{*}{$\begin{array}{l}\text { Baseline } \\
(n=52)\end{array}$} & \multirow[b]{2}{*}{$\begin{array}{l}\text { Memantine } 1 \\
(n=25)\end{array}$} & \multirow[b]{2}{*}{$\begin{array}{l}\text { Placebo } 1 \\
(n=24)\end{array}$} & \multirow[b]{2}{*}{$\begin{array}{l}\text { After wash-out } \\
(n=44)\end{array}$} & \multirow[b]{2}{*}{$\begin{array}{l}\text { Memantine } 2 \\
(n=21)\end{array}$} & \multirow[b]{2}{*}{$\begin{array}{l}\text { Placebo } 2 \\
(n=24)\end{array}$} & \multicolumn{2}{|l|}{ Omnibus test } \\
\hline & & & & & & & $\chi^{2} / F$ & $p$ \\
\hline Memantine-related AE mycosis, $n(\%)$ & & & & & & & $\chi_{4}^{2}=5.750$ & 0.33 \\
\hline None & $46(67.3)$ & $23(92)$ & $20(83.3)$ & $35(81.4)$ & $12(57.1)$ & $22(88.5)$ & & \\
\hline Very little & $2(3.8)$ & $0(0.0)$ & $3(12.5)$ & $3(7.0)$ & $6(28.6)$ & $1(4.2)$ & & \\
\hline Little & $4(7.7)$ & $2(7.7)$ & $1(4.2)$ & $4(9.3)$ & $2(9.5)$ & $1(4.2)$ & & \\
\hline Much & $0(0.0)$ & $0(0.0)$ & $0(0.0)$ & $1(2.3)$ & $0(0.0)$ & $0(0.0)$ & & \\
\hline Very much & $0(0.0)$ & $0(0.0)$ & $0(0.0)$ & $0(0.0)$ & $1(4.8)$ & $0(0.0)$ & & \\
\hline Memantine-related AE dyspnea, $n(\%)$ & & & & & & & $\chi_{5}^{2}=5.329$ & 0.26 \\
\hline None & $26(50.0)$ & $9(36.0)$ & $15(62.5)$ & $19(43.2)$ & $11(52.4)$ & $9(37.5)$ & & \\
\hline Very little & $6(11.5)$ & $10(16.0)$ & $5(20.8)$ & $8(18.2)$ & $5(23.8)$ & $4(16.7)$ & & \\
\hline Little & $13(25.0)$ & $4(40.0)$ & $3(12.5)$ & $14(31.8)$ & $4(19.0)$ & $8(33.3)$ & & \\
\hline Much & $6(11.5)$ & $0(0.0)$ & $1(4.2)$ & $0(0.0)$ & $0(0.0)$ & $3(12.5)$ & & \\
\hline Very much & $1(1.9)$ & $2(8.0)$ & $0(0.0)$ & $2(4.5)$ & $1(4.8)$ & $0(0.0)$ & & \\
\hline \multicolumn{9}{|l|}{ Mean LUNSERS scores (s.D. $)^{a}$} \\
\hline Extrapyramidal symptoms & $13.37(4.06)$ & $13.08(4.18)$ & $13.33(5.31)$ & $12.34(3.94)$ & $13.00(4.30)$ & $12.46(3.12)$ & $F_{1,182}=1.598$ & 0.21 \\
\hline Anticholinergic side effects & $9.87(3.46)$ & $9.13(3.66)$ & $9.92(3.67)$ & $9.26(3.04)$ & $9.80(3.86)$ & $8.33(2.79)$ & $F_{1,185}=1.323$ & 0.25 \\
\hline Other autonomic side effects & $9.27(3.16)$ & $8.42(3.28)$ & $9.33(3.69)$ & $8.95(2.85)$ & $9.11(3.04)$ & $8.37(2.50)$ & $F_{1,184}=0.319$ & 0.57 \\
\hline Allergic reactions & $5.57(1.66)$ & $5.17(1.83)$ & $6.26(2.49)$ & $6.58(2.99)$ & $6.70(3.01)$ & $591(2.52)$ & $F_{1,180}=4.839$ & 0.03 \\
\hline Psychic side effects & $23.63(6.34)$ & $22.36(7.40)$ & $24.58(6.90)$ & $22.44(7.42)$ & $22.75(7.00)$ & $22.08(7.11)$ & $F_{1,183}=1.295$ & 0.26 \\
\hline Hormonal side effects & $8.20(3.03)$ & $7.96(2.22)$ & $8.33(2.22)$ & $8.54(2.68)$ & $8.72(3.12)$ & $7.38(2.27)$ & $F_{1,178}=0.066$ & 0.80 \\
\hline Miscellaneous side effects & $6.43(1.95)$ & $6.54(2.19)$ & $6.96(1.76)$ & $6.86(2.04)$ & $7.37(1.80)$ & $6.83(2.10)$ & $F_{1,184}=1.694$ & 0.20 \\
\hline Red herrings & $14.52(4.72)$ & $14.83(4.35)$ & $14.92(4.49)$ & $15.14(4.94)$ & $15.65(5.21)$ & $14.78(4.73)$ & $F_{1,185}=0.801$ & 0.37 \\
\hline Red herrings $\geqslant 20$ & $0.13(0.35)$ & $0.17(0.38)$ & $0.21(4.95)$ & $0.21(0.41)$ & $0.20(0.41)$ & $0.17(0.39)$ & $F_{1,184}=0.446$ & 0.51 \\
\hline Total & $92.80(21.061)$ & $90.9(23.95)$ & $95.74(0.12)$ & $93.63(23.27)$ & $96.00(27.27)$ & $87.50(21.94)$ & $F_{1,184}=0.041$ & 0.84 \\
\hline Total without red herring items & $78.41(17.12)$ & $75.95(20.16)$ & $80.70(20.47)$ & $78.69(19.37)$ & $80.43(21.96)$ & $72.85(17.66)$ & $F_{1,161}=0.447$ & 0.73 \\
\hline \multicolumn{9}{|l|}{ Laboratory measurement } \\
\hline Mean clozapine plasma level, ng/ml (s.D.) & $421.27(224.61)$ & $515.16(240.43)$ & $376.48(185.11)$ & $461.71(219.61)$ & $403.06(179.90)$ & $436.14(157.07)$ & $F_{1,178}=1.387$ & 0.24 \\
\hline Range, ng/ml & $50-878$ & $101-1060$ & $52-671$ & $60-1080$ & $135-682$ & $200-715$ & & \\
\hline \multicolumn{9}{|l|}{ Physical examination } \\
\hline Mean waist circumference, $\mathrm{cm}$ (S.D.) & $110.04(13.82)$ & $108.32(14.71)$ & $104.04(11.72)$ & $105.50(13.89)$ & $104.41(12.16)$ & $107.88(14.86)$ & $F_{1,181}=1.205$ & 0.27 \\
\hline Mean systolic blood pressure, $\mathrm{mmHg}$ (s.D.) & $134.57(18.77)$ & $169.00(170.28)$ & $130.26(12.59)$ & $130.48(15.94)$ & $125.68(12.82)$ & 130.75 (11.84) & $F_{1,188}=1.954$ & 0.16 \\
\hline Mean diastolic blood pressure, $\mathrm{mmHg}$ (S.D.) & $88.00(9.77)$ & $86.72(10.57)$ & $87.04(8.10)$ & $85.95(9.41)$ & $86.14(9.70)$ & $83.88(7.60)$ & $F_{1,188}=1.084$ & 0.30 \\
\hline
\end{tabular}

AE, Adverse event; LUNSERS, Liverpool University Neuroleptic Side-Effect Rating Scale; S.D., standard deviation.

${ }^{a}$ Extrapyramidal symptoms: items 19, 29, 34, 37, 40, 43, 48; anticholinergic side effects: items 6, 10, 32, 38, 51; other autonomic side effects: items 15, 16, 20, 27, 36; allergic reactions: items 1, 35, 47, 49; psychic side effects: items $2,4,9,14,18,21,23,26,31,41$; hormonal side effects: items 7, 13, 17, 24, 46, 50; miscellaneous side effects: items 5, 12, 39, 44; red herrings: items $3,8,11,12,25,28,30,33,42,45$. 
Table 4. Adverse events ( $n$ )

\begin{tabular}{|c|c|c|c|}
\hline Adverse event & Memantine & $\begin{array}{l}\text { Wash-out } \\
\text { phase }\end{array}$ & Placebo \\
\hline No adverse event & 40 & 47 & 39 \\
\hline Dizziness & 1 & & \\
\hline Nausea and vomiting & & & 1 \\
\hline Constipation & 2 & & 1 \\
\hline Flu-like symptoms & & 1 & 1 \\
\hline $\begin{array}{l}\text { Toxic clozapine plasma } \\
\text { level with flu-like } \\
\text { symptoms }\end{array}$ & & 1 & \\
\hline $\begin{array}{l}\text { Toxic clozapine plasma } \\
\text { level without } \\
\text { symptoms }\end{array}$ & & & 1 \\
\hline Bronchitis & 1 & & \\
\hline $\begin{array}{l}\text { Pneumonia and } \\
\text { urinary tract infection }\end{array}$ & 1 & & \\
\hline Cardiac pain & & & 1 \\
\hline Hip pain & & & 1 \\
\hline Delirium & 1 & & \\
\hline Somnolence & & 1 & \\
\hline Anxiety & 2 & 1 & 3 \\
\hline $\begin{array}{l}\text { Increase in auditory } \\
\text { hallucinations }\end{array}$ & 2 & & \\
\hline $\begin{array}{l}\text { Agitation and verbal } \\
\text { aggression }\end{array}$ & & & 1 \\
\hline $\begin{array}{l}\text { Admission to a } \\
\text { psychiatric unit }\end{array}$ & 2 & 1 & 2 \\
\hline Attempted suicide & & & 1 \\
\hline
\end{tabular}

computerized cognitive test battery to ensure accurate and objective study data with minimized inter-rater variability to evaluate the efficacy of memantine as an adjunct to clozapine in refractory schizophrenia.

Memantine treatment added to clozapine was associated with significant improvement in memory (ES= 0.30). Memory-enhancing effects of the combination therapy of clozapine and memantine may be a result of up-regulation of synaptic NMDA receptor currents in the hippocampus, facilitating induction of long-term potentiation and therefore learning and memory (Kornmeier \& Sosic-Vasic, 2012).

Memantine did not significantly improve executive function $(E S=0.12)$. Executive function is a central cognitive process, involving the PFC, corticocortical and corticosubcortal networks (Evans et al. 1997; Lesh et al. 2011). Enhancement of executive function would require effects on more elaborate networks and several cognitive domains including planning, working memory, strategy use, cognitive flexibility and ability to suppress impulsivity. Apparently, memantine addition does not improve the functioning in these networks, or alternatively longer treatment duration is needed.
Negative symptoms significantly improved with a small ES (ES=0.29). Memantine affected diminished expression to a larger extent than social amotivation. Improvement of expressive deficits may be a result of increased signal transmission with an enhanced signal-to-noise ratio in the PFC (Geerts \& Grossberg, 2006; Hasan et al. 2013) due to the particular combination of clozapine and memantine.

Memantine and placebo did not differ significantly with respect to adverse effects, except for mild and transient allergic symptoms.

Improvement of cognitive disturbances and negative symptoms is an important goal for treatment-resistant schizophrenia. Together these symptoms have a more pronounced impact on psychosocial functioning and quality of life than positive symptoms (Ventura et al. 2015). Clinical impairment of memory is one of the major disabilities in schizophrenia. Specifically, verbal memory is a strong predictor of functional outcome (Green, 1996). Favorable effects of memantine in combination with clozapine may be based on the neuroprotective properties and pharmacodynamic activities of this combination. In a recent proton magnetic resonance spectroscopy study anterior cingulate cortex glutamate levels were elevated in patients with treatment-resistant schizophrenia compared with patients with treatmentresponsive schizophrenia, endorsing our hypothesis that memantine is specifically efficacious in refractory schizophrenia (Mouchlianitis et al. 2015).

The effect of memantine augmentation that we found is in line with the improvement of negative symptoms that has been found in five trials of addition of a glutamate antagonist to clozapine in partially responding schizophrenia patients (Goff et al. 2007 (study 926); Zoccali et al. 2007; Afshar et al. 2008; de Lucena et al. 2009; Muscatello et al. 2010). Topiramate and lamotrigine both showed favorable effects on negative symptoms in each of two trials, with ESs varying from 0.76 to 1.37 and 0.66 to 1.21 , respectively. Cognitive functioning had been assessed with different cognitive test batteries in five double-blind, placebocontrolled randomized trials of clozapine augmentation with glutamate antagonists. In one trial of topiramate (Muscatello et al. 2010) and two trials of lamotrigine add-on therapy to clozapine (Goff et al. 2007 (study 926); Vayısoğlu et al. 2013), cognitive functions did not significantly change compared with placebo. However, two trials showed favorable results on cognition (Zoccali et al. 2007; de Lucena et al. 2009). In the study by Zoccali et al. (2007), the only cognitive function that significantly improved was semantic fluency after 24 weeks of addition of lamotrigine $200 \mathrm{mg}$ daily.

The differences and similarities between our results and that of the 12-week memantine add-on study by 
de Lucena et al. (2009) are striking. De Lucena et al. (2009) found exceptionally large ESs on all treatment outcome parameters. Most striking was the large ES of 3.33 concerning negative symptoms (de Lucena et al. 2009). But also the effect on global cognitive functioning $(\mathrm{ES}=-1.32)$, as measured by the Mini-Mental State Examination (MMSE) (Folstein et al. 1975), was substantial. Caution is necessary, for efficacy of memantine was perhaps overestimated partly by chance in this relatively small sample study (21 patients) (Sinclair \& Adams, 2014; Tajika et al. 2015). The crossover design of our larger double-blind randomized clinical trial eliminated the influence of betweensubject variability on effect. The MMSE, used by de Lucena et al. (2009), does not measure executive functioning and detects cognitive deficits only at an advanced stage, because tasks for language and memory functions are extremely simple (Feher et al. 1992). We used a more sensitive and comprehensive cognitive test battery developed for assessment of cognitive impairments in schizophrenia intervention studies (Levaux et al. 2007). The Brief Psychiatric Rating Scale (BPRS), used by de Lucena et al. (2009), merely covers three negative symptom items (blunted affect, emotional withdrawal and psychomotor retardation). We used the more sensitive PANSS scale with seven items on the negative symptom subscale (Eckert et al. 1996) and four additional items on the general symptom subscale in the post-hoc analysis (Liemburg et al. 2013). Our patient population differed compared with that of the first memantine augmentation to clozapine study in mean age (42.35 v. 34.67 years) and mean duration of illness (22.88 years $v .17 .84$ years), CGI-S scores (6.15 v. 5.34) and mean total PANSS and total BPRS scores (81.21 and 14.38, respectively), suggesting that our patient population was more severely ill than were patients in the study by de Lucena et al. (2009). Although in our patients the severity of residual negative symptoms was comparable with the severity of persistent positive symptoms (mean PANSS negative subscale $=22.12$, S.D. $=5.86$; mean PANSS positive subscale $=21.02$, s.D. $=6.34$ ), negative symptoms prevailed in the study by de Lucena et al. (2009). While mean total BPRS score (14.38) corresponds with 'markedly ill' according to CGI-S (score 5) in the de Lucena study, our patient population was rated as severely ill (mean CGI-S score 6.15) due to prominent cognitive impairment. These differences between studies may partly explain the more moderate beneficial effects of memantine addition in our study. However, the difference in ES for all symptom domains between the de Lucena study and ours is very large. It has been demonstrated that among randomized trials, initially stronger effects are not unusual (Ioannidis, 2005; Tajika et al. 2015). Memantine was generally well tolerated in both studies. Although there were no drop-outs in the first study, one participant discontinued in our trial because of dizziness in the memantine phase.

The results of our study are limited by the short memantine treatment duration of 12 weeks. A longer treatment duration may result in more pronounced treatment effects associated with an improved glutamatergic balance, as was found in patients with AD. In a meta-analysis of six randomized, placebocontrolled trials of memantine treatment in 2311 patients with $\mathrm{AD}$, symptoms of delusion were more improved after 24 to 28 weeks compared with 12 weeks (Puangthong \& Hsiung, 2009). Furthermore, the crossover design resulted in carryover effects on several measures, including verbal memory and all PANSS subscales, despite a 2-week placebo wash-out period. Although the model controls for carryover effects, these cannot be discarded completely. Practice effects were minimized due to the fact that the number of subjects randomized to the placebo and memantine groups before crossover was the same and a parallel form was used for verbal memory. Tests on executive function, depending on strategy, show strong practice effects and low test-retest reliability (Lowe \& Rabbitt, 1998). However, there is no research on practice effects using the CANTAB in patients with severe cognitive disturbances suffering from refractory schizophrenia. Although our study included more patients than the first investigation by de Lucena et al. (2009) our sample size is still relatively small (Sinclair \& Adams, 2014). The results of our study need to be validated in a randomized multicenter long-term treatment study with a large sample size and enough power to clearly show a reduction of at least $25 \%$ of the baseline score in order to help further evaluate pro-cognitive properties of memantine in combination with clozapine in refractory patients and its potential to reduce negative symptoms associated with schizophrenia (Leucht et al. 2009).

In conclusion, we found evidence that addition of memantine may be a well-tolerated treatment option for cognitive impairments and negative symptoms in patients with clozapine-refractory schizophrenia, deserving further study.

\section{Supplementary material}

For supplementary material accompanying this paper visit http://dx.doi.org/10.1017/S0033291716000398

\section{Acknowledgements}

We thank the participants of this study and their care providers for their assistance, enthusiasm and support. We also thank M. Monden and Dr J. B. Deijen for their 
contribution to the training of the raters. This research received no specific grant from any funding agency, commercial or not-for-profit sectors. This work was supported by the Community Mental Health Division of Mental Health Service Organization North Holland North. The study was partially funded by the 2012 Care Innovation Prize of Mental Health Service Organization North Holland North. Both verum and placebo tablets were provided by H. Lundbeck A/S at no cost. H. Lundbeck A/S did not play any role in the design, conduct, analysis or interpretation of the trial.

\section{Declaration of Interest}

S.R.T.V. and J.D.S. report no financial relationships with commercial interests. P.F.J.S. reports personal fees from $\mathrm{H}$. Lundbeck $\mathrm{A} / \mathrm{S}$, outside the submitted work and he is a board member of the Dutch Clozapine Collaboration Group. L.d.H. has received investigator-led research grants or recompense for presenting his research from Eli Lilly, Bristol-Myers Squibb, Janssen-Cilag and AstraZeneca.

\section{Notes}

${ }^{1}$ The full results of the study are available by request from the first author (S.R.T.V.).

2 A period effect was included as a control only as the study does not have sufficient power to test for such an effect directly. Further, a period effect was not hypothesized.

\section{References}

Afshar H, Roohafza H, Mousavi G, Golchin S, Toghianifar N, Sadeghi M, Talaei M (2008). Topiramate add-on treatment in schizophrenia: a randomised, double blind, placebo controlled clinical trial. Journal of

Psychopharmacology 23, 157-162.

Andreasen NC, Carpenter Jr. WT, Kane JM, Lasser RA, Marder SR, Weinberger DR (2005). Remission in schizophrenia: proposed criteria and rationale for consensus. American Journal of Psychiatry 162, 441-449.

Areosa SA, Sherriff F, McShane R (2005). Memantine for dementia. Cochrane Database of Systematic Reviews, Issue 2, CD003154.

Barnett JH, Robbins TW, Leeson VC, Sahakian BJ, Joyce EM, Blackwell AD (2010). Assessing cognitive function in clinical trials of schizophrenia. Neuroscience and Biobehavioral Reviews 34, 1161-1177.

Bliss TV, Collingridge GL (1993). A synaptic model of memory: long-term potentiation in the hippocampus. Nature 361, 31-39.

Bressan RA, Pilowsky LS (2000). Imaging the glutamatergic system in vivo - relevance to schizophrenia. European Journal of Nuclear Medicine 27, 1723-1731.
Cohen J (1988). Statistical Power Analysis for the Behavioral Sciences, 2nd edn. Erlbaum: Hillsdale, NJ.

Day JC, Wood G, Dewey M, Bentall RP (1995). A self-rating scale for measuring neuroleptic side-effects: validation in a group of schizophrenic patients. British Journal of Psychiatry 166, 650-653.

de Lucena D, Fernandes BS, Berk M, Dodd S, Medeiros DW, Pedrini M, Kunz M, Gomes FA, Giglio LF, Lobato MI, Belmonte-de-Abreu PS, Gama CS (2009). Improvement of negative and positive symptoms in treatment-refractory schizophrenia: a double-blind, randomized, placebo-controlled trial with memantine as add-on therapy to clozapine. Journal of Clinical Psychiatry 70, 1416-1423.

Eckert S, Diamond PM, Miller AL, Velligan DI, Funderburg LG, True JF (1996). A comparison of instrument sensitivity to negative symptom change. Psychiatry Research 63, 67-75.

Evans JJ, Chua SE, McKenna PJ, Wilson BA (1997). Assessment of the dysexecutive syndrome in schizophrenia. Psychological Medicine 27, 635-646.

Farlow MR, Graham SM, Alva G (2008). Memantine for the treatment of Alzheimer's disease: tolerability and safety data from clinical trials. Drug Safety 31, 577-585.

Feher EP, Mahurin RK, Doody RS, Cooke N, Sims J, Pirozzolo FJ (1992). Establishing the limits of the Mini-Mental State: examination of subtests. Archives of Neurology 49, 87-92.

Folstein MF, Folstein SE, McHugh PR (1975). 'Mini-mental state'. A practical method for grading the cognitive state of patients for the clinician. Journal of Psychiatric Research 12, 189-198.

Geerts H, Grossberg GT (2006). Pharmacology of acetylcholinesterase inhibitors and $N$-methyl-D-aspartate receptors for combination therapy in the treatment of Alzheimer's disease. Journal of Clinical Pharmacology 46, 8S-16S.

Goff DC, Keefe R, Citrome L, Davy K, Krystal JH, Large C, Thompson TR, Volavka J, Webster EL (2007). Lamotrigine as add-on therapy in schizophrenia: results of 2 placebocontrolled trials. Journal of Clinical Psychopharmacology 27, 582-589.

Green MF (1996). What are the functional consequences of neurocognitive deficits in schizophrenia? American Journal of Psychiatry 153, 321-330.

Guy W (1976). Clinical Global Impression Scale. In ECDEU Assessment Manual for Psychopharmacology, revised edn. (ed W. Guy), pp. 218-222. US Department of Health, Education and Welfare, ADAMHA, NIMH Psychopharmacology Research Branch: Rockville, MD.

Hasan A, Falkai P, Wobrock T (2013). Transcranial brain stimulation in schizophrenia: targeting cortical excitability, connectivity and plasticity. Current Medicinal Chemistry 20, 405-413.

Hasan A, Falkai P, Wobrock T, Lieberman J, Glenthoj B, Gattaz WF, Thibaut F, Möller HJ; World Federation of Societies of Biological Psychiatry (WFSBP) Task Force on Treatment Guidelines for Schizophrenia (2012). World Federation of Societies of Biological Psychiatry (WFSBP) Task Force on Treatment Guidelines for Schizophrenia. 
World Federation of Societies of Biological Psychiatry (WFSBP) Guidelines for Biological Treatment of Schizophrenia, part 1: update 2012 on the acute treatment of schizophrenia and the management of treatment resistance. World Journal of Biological Psychiatry 13, 318-387.

Homayoun H, Moghaddam B (2007). NMDA receptor hypofunction produces opposite effects on prefrontal cortex interneurons and pyramidal neurons. Journal of Neuroscience 27, 11496-11500.

Howes OD, Kapur S (2009). The dopamine hypothesis of schizophrenia: version III - final common pathway. Schizophrenia Bulletin 35, 549-562.

Ioannidis JP (2005). Contradicted and initially stronger effects in highly cited clinical research. Journal of the American Medical Associaton 294, 218-228.

Javitt DC, Zukin SR (1991). Recent advances in the phencyclidine model of schizophrenia. American Journal of Psychiatry 148, 1301-1308.

Joshi I, Yang Y-M, Wang L-Y (2007). Cellular/molecular coincident activation of metabotropic glutamate receptors and NMDA receptors (NMDARs) downregulates perisynaptic/extrasynaptic NMDARs and enhances highfidelity neurotransmission at the developing calyx of the held synapse. Journal of Neuroscience 27, 9989-9999.

Kantrowitz JT, Javitt DC (2010). N-methyl-D-aspartate (NMDA) receptor dysfunction or dysregulation: the final common pathway on the road to schizophrenia? Brain Research Bulletin 83, 108-121.

Kay SR, Fiszbein A, Opler LA (1987). The Positive and Negative Syndrome Scale (PANSS) for schizophrenia. Schizophrernia Bulletin 13, 261-276.

Kornmeier J, Sosic-Vasic Z (2012). Parallels between spacing effects during behavioural and cellular learning. Frontiers in Human Neuroscience 6, 203.

Lee JG, Lee SW, Lee BJ, Park SW, Kim GM, Kim YH (2012). Adjunctive memantine therapy for cognitive impairment in chronic schizophrenia: a placebo-controlled pilot study. Psychiatry Investigation 9, 166-173.

Lesh TA, Niendam TA, Minzenberg MJ, Carter CS (2011). Cognitive control deficits in schizophrenia: mechanisms and meaning. Neuropsychopharmacology 36, 316-338.

Leucht S, Davis JM, Engel RR, Kissling W, Kane JM (2009). Definitions of response and remission in schizophrenia: recommendations for their use and their presentation. Acta Psychiatrica Scandinavica. Supplementum 438, 7-14.

Levaux MN, Potvin S, Sepehry AA, Sablier J, Mendrek A, Stip E (2007). Computerized assessment of cognition in schizophrenia: promises and pitfalls of CANTAB. European Psychiatry 22, 104-115.

Lieberman JA, Papadakis K, Csernansky J, Litman R, Volavka J, Jia XD, Gage A; MEM-MD-29 Study Group (2009). A randomized, placebo-controlled study of memantine as adjunctive treatment in patients with schizophrenia. Neuropsychopharmacology 34, 1322-1329.

Liemburg E, Catelein S, Stewart R, van der Gaag M, Aleman A, Knegtering H; Genetic Risk and Outcome of Psychosis (GROUP) Investigators (2013). Two subdomains of negative symptoms in psychotic disorders: established and confirmed in two large cohorts. Journal of Psychiatric Research 47, 718-725.

Little RJA, Rubin DB (2002). Statistical Analysis with Missing Data, 2nd edn. John Wiley: New York.

Lowe C, Rabbitt P (1998). Test/re-test reliability of the CANTAB and ISPOCD neuropsychological batteries: theoretical and practical issues. Cambridge

Neuropsychological Test Automated Battery. International Study of Post-Operative Cognitive Dysfunction.

Neuropsychologia 36, 915-923.

Millan MJ, Fone K, Steckler T, Horan WP (2014). Negative symptoms of schizophrenia: clinical characteristics, pathophysiological substrates, experimental models and prospects for improved treatment. European

Neuropsychopharmacology 24, 645-692.

Mouchlianitis E, Bloomfield MA, Law V, Beck K, Selvaraj S, Rasquinha N, Waldman A, Turkheimer FE, Egerton A, Stone J, Howes OD (2015). Treatment-resistant schizophrenia patients show elevated anterior cingulate cortex glutamate compared to treatment-responsive. Schizophrenia Bulletin pii, sbv151.

Muscatello MR, Bruno A, De Fazio P, Segura-Garcia C, Pandolfo G, Zoccali R (2014). Augmentation strategies in partial responder and/or treatment-resistant schizophrenia patients treated with clozapine. Expert Opinion on Pharmacotherapy 15, 2329-2345.

Muscatello MR, Bruno A, Pandolfo G, Micò U, Bellinghieri PM, Scimeca G, Cacciola M, Campolo D, Settineri S, Zoccali R (2010). Topiramate augmentation of clozapine in schizophrenia: a double-blind, placebo-controlled study. Journal of Psychopharmacology 25, 667-674.

Nuechterlein KH, Green MF, Kern RS, Baade LE, Barch DM, Cohen JD, Essock S, Fenton WS, Frese 3rd FJ, Gold JM, Goldberg T, Heaton RK, Keefe RS, Kraemer H, Mesholam-Gately R, Seidman LJ, Stover E, Weinberger DR, Young AS, Zalcman S, Marder SR (2008). The MATRICS consensus cognitive battery, part 1: test selection, reliability and validity. American Journal of Psychiatry 165, 203-213.

Orellana G, Slachevsky A (2013). Executive functioning in schizophrenia. Frontiers in Psychiatry 4, 35.

Overbeek T, Schruers K, Griez E (1999). MINI. Mini International Neuropsychiatric Interview. Dutch version 5.0.0. $D S M-I V$. University of Maastricht: Maastricht, the Netherlands.

Parsons CG, Gilling K (2007). Memantine as an example of a fast, voltage-dependent, open channel

$\mathrm{N}$-methyl-D-aspartate receptor blocker. Methods of Molecular Biology 403, 15-36.

Puangthong U, Hsiung GY (2009). Critical appraisal of the long-term impact of memantine in treatment of moderate to severe Alzheimer's disease. Neuropsychiatric Disease and Treatment 5, 553-561.

Putt M, Chinchilli VM (1999). A mixed effects model for the analysis of repeated measures cross-over studies. Statistics in Medicine 30, 3037-3058.

Rezaei F, Mohammad-Karimi M, Seddighi S, Modabbernia A, Ashrafi M, Salehi B, Hammidi S, Motasami H, Hajiaghaee R, Tabrizi M, Akhondzadeh S (2013). 
Memantine add-on to risperidone for treatment of negative symptoms in patients with stable schizophrenia: randomized, double-blind, placebo-controlled study. Journal of Clinical Psychopharmacology 33, 336-342.

Schulte PFJ (2003). What is an adequate trial with clozapine? Therapeutic drug monitoring and time to response in treatment-refractory schizophrenia. Clinical Pharmacokinetics 42, 607-618.

Sinclair D, Adams CE (2014). Treatment resistant schizophrenia: a comprehensive survey of randomized controlled trials. BMC Psychiatry 14, 253.

Singer JD, Willett JB (editors) (2003). Applied Longitudinal Data Analysis: Modeling Change and Event Occurrence. Oxford University Press: New York.

SPSS Inc. (2014). SPSS Statistics version 22.0.0. SPSS Inc.: Chicago, IL.

Stone JM, Morrison PD, Pilowsky LS (2007). Review: glutamate and dopamine dysregulation in schizophrenia a synthesis and selective review. Journal of Psychopharmacoly 21, 440-452.

Tajika A, Ogawa Y, Takeshima N, Hayasaka Y, Furukawa TA (2015). Replication and contradiction of highly cited research papers in psychiatry: 10-year follow-up. British Journal of Psychiatry 207, 357-365.

Tanahashi S, Yamamura S, Nakagawa M, Motomura E, Okada M (2012). Clozapine, but not haloperidol, enhances glial D-serine and L-glutamate release in rat frontal cortex and primary cultured astrocytes. British Journal of Pharmacology 165, 1543-1555.

van Veldhuizen JR (2007). FACT: a Dutch version of ACT. Community Mental Health Journal 43, 421-433.

Vayısoğlu S, Anıl Yağcığlu AE, Yağcioğlu S, Karahan S, Karcı O, Gürel SC, Yazıcı MK (2013). Lamotrigine augmentation in patients with schizophrenia who show partial response to clozapine treatment. Schizophrenia Research 143, 207-214.
Veerman SRT, Schulte PF, Begemann MJ, de Haan L (2014a) Non-glutamatergic clozapine augmentation strategies: a review and meta-analysis. Pharmacopsychiatry 47, 231-238.

Veerman SRT, Schulte PF, Begemann MJ, Engelsbel F, de Haan L (2014b). Clozapine augmented with glutamate modulators in refractory schizophrenia: a review and metaanalysis. Pharmacopsychiatry 47, 185-194.

Veerman SRT, Schulte PF, de Haan L (2014c). The glutamate hypothesis: a pathogenic pathway from which pharmacological interventions have emerged. Pharmacopsychiatry 47, 121-130.

Ventura J, Subotnik KL, Gitlin MJ, Gretchen-Doorly D, Ered A, Villa KF, Hellemann GS, Nuechterlein KH (2015). Negative symptoms and functioning during the first year after a recent onset of schizophrenia and 8 years later. Schizophrenia Research 161, 407-413.

Wesemann W, Sontag KH, Maj J (1983). Pharmacodynamics and pharmacokinetics of memantine. Arzniemittelforschung 33, 1122-1134.

Winblad B, Jones RW, Wirth Y, Stöffler A, Möbius HJ (2007). Memantine in moderate to severe Alzheimer's disease: a meta-analysis of randomised clinical trials. Dementia and Geriatric Cognitive Disorders 24, 20-27.

World Medical Association (2013). World Medical Association Declaration of Helsinki: ethical principles for medical research involving human subjects. Journal of the American Medical Association 310, 2191-2194.

Yeun EY, Zhong P, Yan Z (2010). Homeostatic regulation of glutamatergic transmission by dopamine D4 receptors. Proceedings of the National Academy of Sciences USA 107, 22308-22313.

Zoccali R, Muscatello MR, Bruno A, Cambria R, Micò U, Spina E, Meduri M (2007). The effect of lamotrigine augmentation of clozapine in a sample of treatmentresistant schizophrenic patients: a double-blind, placebocontrolled study. Schizophrenia Research 93, 109-116. 